Progress in

Physical Geography

\title{
Estimating habitat extent and carbon loss from an eroded Northern blanket bog using UAV derived imagery and topography.
}

\begin{tabular}{|c|c|}
\hline Journal: & Progress in Physical Geography \\
\hline Manuscript ID & PPG-17-088.R3 \\
\hline Manuscript Type: & Main Article \\
\hline Keywords: & $\begin{array}{l}\text { Peatlands, Unmanned Aerial Vehicle, Structure from Motion, Habitat, } \\
\text { Blanket Bog, Random Forest }\end{array}$ \\
\hline Abstract: & $\begin{array}{l}\text { Peatlands are important reserves of terrestrial carbon and biodiversity, } \\
\text { and given that many peatlands across the UK and Europe exist in a } \\
\text { degraded state, their conservation is a major area of concern, and a } \\
\text { focus of considerable research. Aerial surveys are valuable tools for } \\
\text { habitat mapping and conservation and provide useful insights into their } \\
\text { condition. We investigate how Structure from Motion (SfM) } \\
\text { photogrammetry derived topography and habitat classes may be used to } \\
\text { derive an estimate of carbon loss from erosion features in a remote } \\
\text { blanket bog habitat. An autonomous, unmanned, aerial, fixed wing } \\
\text { remote sensing platform (Quest UAV } 300^{\mathrm{TM}} \text { ), collected imagery over } \\
\text { Moor House - Upper Teesdale National Nature Reserve, a site with a high } \\
\text { degree of peatland erosion. The images were used to generate point } \\
\text { clouds into orthomosaics and digital surface models using SfM } \\
\text { photogrammetry techniques, georeferenced, and subsequently used to } \\
\text { classify vegetation and peatland features. A classification of peatbog } \\
\text { feature types was developed using a random forest classification model } \\
\text { trained on field survey data and applied to UAV-captured products } \\
\text { including the orthomosaic, digital surface model and derived surfaces } \\
\text { such as topographic index, slope and aspect maps. Using the area } \\
\text { classified as eroded peat, and the derived digital surface model, we } \\
\text { estimated a loss of } 438 \text { tonnes of carbon from a single gully. The UAV } \\
\text { system was relatively straightforward to deploy in such a remote and } \\
\text { unimproved area. SfM photogrammetry, imagery and random forest } \\
\text { modelling obtained classification accuracies of between } 42 \% \text { and } 100 \% \text {, } \\
\text { and was able to discern between bare peat, saturated bog and } \\
\text { sphagnum, habitats. This paper shows what can be achieved with a low- } \\
\text { cost UAV equipped with consumer grade camera equipment, and } \\
\text { relatively straightforward ground control, and demonstrates their } \\
\text { potential for the carbon and peatland conservation research community. }\end{array}$ \\
\hline
\end{tabular}

\section{SCHOLARONE Manuscripts}


Page 1 of 22

\section{Abstract}

2 Peatlands are important reserves of terrestrial carbon and biodiversity, and given that many

3 peatlands across the UK and Europe exist in a degraded state, their conservation is a major area

4 of concern, and a focus of considerable research. Aerial surveys are valuable tools for habitat

5 mapping and conservation and provide useful insights into their condition. We investigate how

6 Structure from Motion (SfM) photogrammetry derived topography and habitat classes may be

7 used to derive an estimate of carbon loss from erosion features in a remote blanket bog habitat.

8 An autonomous, unmanned, aerial, fixed wing remote sensing platform (Quest UAV 300 ${ }^{\mathrm{TM}}$ ),

9 collected imagery over Moor House - Upper Teesdale National Nature Reserve, a site with a

10 high degree of peatland erosion. The images were used to generate point clouds into

11 orthomosaics and digital surface models using SfM photogrammetry techniques, georeferenced,

12 and subsequently used to classify vegetation and peatland features. A classification of peatbog

13 feature types was developed using a random forest classification model trained on field survey

14 data and applied to UAV-captured products including the orthomosaic, digital surface model and

15 derived surfaces such as topographic index, slope and aspect maps. Using the area classified as

16 eroded peat, and the derived digital surface model, we estimated a loss of 438 tonnes of carbon

17 from a single gully. The UAV system was relatively straightforward to deploy in such a remote

18 and unimproved area. SfM photogrammetry, imagery and random forest modelling obtained

19 classification accuracies of between $42 \%$ and $100 \%$, and was able to discern between bare peat,

20 saturated bog and sphagnum, habitats. This paper shows what can be achieved with a low-cost

21 UAV equipped with consumer grade camera equipment, and relatively straightforward ground

22 control, and demonstrates their potential for the carbon and peatland conservation research 23 community. 
Page $\mathbf{2}$ of $\mathbf{2 2}$

Blanket bogs are tree-less habitats that form in cool, wet, oceanic climates dominated by vascular plants such as Eriophorum and Calluna spp and cushion forming bryophytes such as Sphagnum spp. They cover roughly 4,000,000 $\mathrm{km}^{2}$ land and have been estimated to store 500-600 gigatonnes of carbon (Yu, 2012, Holden, 2005). Because of this enormous carbon (C) stock, peatland $\mathrm{C}$ represents an important reservoir within the global C cycle (Freeman et al. 2001). Over $80 \%$ of UK peatlands are in a degraded state due mainly to past drainage, fire and grazing (Joosten et al., 2012). It has been estimated that $16 \%$ of the global peatland reserve has been degraded and lost owing to human activities (Littlewood, 2010). Recently, the increased awareness of this global decline has resulted in a range of directives and guidelines, and in the UK conservation management aimed at restoring peatlands has been implemented under the EU habitats directive (Evans et al. 2014). From an ecological perspective, peatlands also represent an important habitat for a number of rare and endangered plant and animal species.

The monitoring of blanket bogs is particularly challenging, as a consequence of their remoteness and physical complexity, but a number of methods have been developed (Mc Morrow et al., 2004, Evans and Lindsay, 2010, Glendell et al., 2017). Remote sensing techniques using commercial satellite data are well established, and offer data at sub-10 m resolution. To date the high cost of these data, and limitations due to cloud coverage or view angles, have limited the value of Earth Observation (EO)-based data for this type of surveillance. Recently however, new methods for capturing high resolution scenes of remote peatlands have emerged.

Unmanned aerial vehicles (UAVs) now offer the ecologist a useful platform for capturing images of peatlands closer to the ground, i.e. below normal cloud levels. The data can be accessed immediately, and ground truthing field surveys can be timed to coincide precisely with the time 
48 of flights. UAVs allow the collection of higher resolution imagery at a lower cost than manned 49 aircraft or commercial satellite-data. UAV imagery resolution is typically less than $5 \mathrm{~cm}$ per 50 pixel, whereas manned aircraft resolution is typically $25-12.5 \mathrm{~cm}$ per pixel and satellite 51 resolution is at best around $50 \mathrm{~cm}$ per pixel (Toth and Jozkow, 2016). Imagery acquired by the 52 older generation of satellite sensors, at around $30 \mathrm{~m}$ per pixel, may pick up the dominant habitat 53 but tend to lack the resolution required to represent the complex mosaics characteristic of many 54 natural and semi-natural habitats (Boyle et al, 2014).

55 Image mosaic preparation, i.e. stitching the imagery together using off the shelf tools, remains a 56 challenge due to the heterogeneity of habitats within landscape imagery, but is now automated in 57 many software packages, and orthomosaics can be readily obtained. An important recent 58 breakthrough is that a high resolution digital surface model (DSM) may also be obtained through 59 Structure from Motion (SfM) photogrammetry processing in such software, since information on 60 surface structure derived from the DSM may inform the relationship between subsequent 61 classifications and peatland condition (Anderson et al. 2010). The combination of spectral data, 62 DSM and classification techniques already available in the remote sensing scientist's toolbox 63 (Random Forest Classification, maximum likelihood etc.) now provide huge potential to develop 64 and calibrate an effective UAV-imagery based tool for peatland monitoring. Spectral and 65 textural information have been combined successfully using Random Forest (a method based on 66 machine learning that uses ensembles of decision trees to assign classes - see Breiman (2001) 67 and Gislason et al. (2006)) for predicting forest condition (Dye et al. 2012), and for looking at 68 fine scale coastal structures (Juel et al. 2015). Whilst uncertainties certainly exist in the use of 69 SfM, uncertainties are simultaneously reduced if one considers how little detailed surface 
70 topographic information exists for remote gully environments such as at Moor House NNR, used

71 in this study.

72 In this paper we explore the potential of high spatial resolution $(4 \mathrm{~cm})$ true-colour (RGB)

73 imagery obtained from a UAV platform for mapping and ecologically classifying a remote

74 upland blanket bog in northern England. Since the surface topography of northern blanket bog

75 habitats determine the presence of Sphagnum, Eriophorum or Calluna habitats, the models

76 presented here incorporate a compound topographic index (CTI). Specifically we compared two

77 input data scenarios and quantified the difference in the resulting classification:

Scenario 1: True-Colour orthomosaic only

Scenario 2: True-Colour orthomosaic, plus slope, CTI and aspect

80 We used two scenarios so that the effect that texture information might have on the accuracy of

81 the peatland classification could be investigated. In particular we aimed to investigate the

82 capability of the imagery to define small patches $(<1 \mathrm{~m}$ width) of the fine scale habitats such as

83 Sphagnum (a positive indicator of high water table), or exposed peat (negative indicator) that are

84 poorly mapped by coarser resolution EO data. We considered how the information content of the 85 input data could be maximised to improve classification accuracy. Finally we provide an 86 estimate of carbon loss from an area of eroded peat based on: the elevation model, the classified 87 eroded peat area, and the carbon density measurements taken through surveys at the site.

\section{Methodology}

\section{Description of the study site}

90 The UK Environmental Change Network (ECN) site, Moor House, Upper Teesdale, (OS Grid 91 reference NY75303331), in the North Pennine uplands (Figure 1), is England's highest and 


\section{Page $\mathbf{5}$ of $\mathbf{2 2}$}

92 largest terrestrial National Nature Reserve (NNR). It is a UNESCO Biosphere Reserve and a 93 European Special Protection Area. Habitats include exposed summits, extensive blanket 94 peatlands, upland grasslands and pastures grazed mainly by sheep, hay meadows and deciduous 95 woodland. A large part of the catchment of the River Tees, from its source near Great Dun Fell 96 to High Force waterfall, is included in the reserve. The site comprises two areas divided by Cow 97 Green Reservoir. The Moor House area extends from the upper edge of enclosed land in the 98 Eden Valley, over Great Dun Fell (848 m), Little Dun Fell and Knock Fell to the upper end of 99 Cow Green Reservoir on the River Tees. The gently sloping eastern side of the area is overlain 100 by poorly-drained glacial till, which has led to the development of blanket bog with peat 2-3 m 101 deep. The vegetation is dominated by Eriophorum spp., Calluna vulgaris and Sphagnum spp. 102 with patches of eroded blanket bog without vegetation cover. The western side is steeper and the 103 soils and vegetation are more variable. The area includes unique communities of arctic-alpine 104 plants and upland flora and fauna of conservation interest.

\section{Field Data Collection}

106 A vegetation and landform survey was carried out between June and September 2008, and May 107 and July 2009, as part of a wider objective to update habitat mapping within the Troutbeck 108 catchment, a small catchment within the Moor House area (Rose et al., 2016). Quadrat sampling 109 points were located systematically at the mid-points of a $100 \mathrm{~m}$ grid using ArcGIS (ESRI) 110 (Figure 1), and located in the field using a handheld GPS unit (Garmin eTrex Vista HCx, 111 accuracy $<3 m)$.

112 Data were entered into a GIS database in the field using a modified version of the 'CS Surveyor' 113 digital data capture system designed for Countryside Survey 2007 (Maskell et al. 2008). A 2 x 2 $114 \mathrm{~m}^{2}$ quadrat was placed at each plot, with the diagonal orientated north-south. Within each 
Page $\mathbf{6}$ of $\mathbf{2 2}$

115 quadrat, percentage cover of all vascular plant species, and a restricted list of bryophytes, was

116 determined using visual estimation according to the technique described in Maskell et al. (2008).

\section{Airborne Data Collection}

118 The airborne campaigns were conducted in summer 2015 using an unmanned aerial vehicle 119 (UAV) operated by the NERC Centre for Ecology and Hydrology. The UAV, a QuestUAV $120300^{\mathrm{TM}}$, carried a Panasonic Lumix DMC-LX7 with a 3648 x 2736 pixel detector that captured 121 JPEG images at $\mathrm{f} / 1.4$ and $1 / 2500$ s with an angular field of view of $73.7 \times 53.1$, providing $\sim 4.5 \mathrm{~cm}$ 122 pixel $^{-1}$ resolution at $122 \mathrm{~m}$ above ground level (AGL). The UAV was a $2 \mathrm{~m}$ wingspan fixed-wing 123 platform with up to $1 \mathrm{~h}$ endurance at $3 \mathrm{~kg}$ take-off weight and $63 \mathrm{~km} / \mathrm{h}$ ground speed. The UAV 124 platform followed four flight plans over a $2400 \mathrm{~m}^{2}$ area, which had been designed to ensure 125 sharp imagery was obtained at high resolution, which had large across- and along-track 126 overlapping. The UAV took 20 minutes to complete each flight plan at $122 \mathrm{~m}$ AGL. It was flown 127 by two trained operators and controlled by an autopilot for fully autonomous flying (Skycircuits 128 SC2, Southampton, UK). The autopilot had a dual CPU controlling an integrated attitude heading 129 reference system (AHRS) with a comprehensive onboard sensor suite (3-axis accelerometers, 3130 axis gyroscopes, 3-axis magnetometers, dynamic and static pressure sensors). The ground control 131 station and the UAV were radio linked, transmitting position, altitude, and status data at $2.4 \mathrm{gHz}$. 132 The weather on the date of the flights was clear and free of cloud. Flights were conducted 133 between 10:00 and 16:00 to minimise effects of shadow. Wind speeds remained below 15 knots 134 on all flights. The integrated onboard GPS updated at between 4 and $10 \mathrm{~Hz}$ and had a positional 135 accuracy of $+/-3 \mathrm{~m}$.

137 Airborne Data Processing 
Page $\mathbf{7}$ of $\mathbf{2 2}$

138 The imagery was synchronized using the GPS position and the triggering time recorded on the 139 flight logger for each image, and these were then used for the generation of an orthomosaic and 140 digital surface model (DSM). Flight altitude data were also logged and images were geotagged 141 with xyz coordinates for use by the image processing software. Image processing of the image 142 collection was performed in Agisoft PhotoScan Professional v1.4.2 (C) 2018 Agisoft LLC, 27 143 Gzhatskaya st., St. Petersburg, Russia). Details of the steps taken in acquisition, processing and 144 modelling are shown in Figure 2. The software initially aligned the camera positions based on 145 the GPS coordinates from the flight log. Ground control points were added based on known 146 locations of static features located using $25 \mathrm{~cm}$ Next Perspectives Aerial Photography RGB 147 Product (Infoterra Ltd). Height values were based on values obtained from the Environment 148 Agency LIDAR digital surface model which covered parts of the study area. Then a 3D point 149 cloud, and 3D mesh representing the land surface was generated at a density of 160 points $\mathrm{m}^{-2}$, 150 this mesh was then used for orthomosaic and DSM generation at $0.04 \mathrm{~m}$ resolution. The $\mathrm{Z}$ error 151 was computed by deducting check points $Z$ values from the DSM value at the same point. The 152 image processing settings and associated calculated accuracies are shown in Tables 4 and 5. 153 During the stages of processing checks were made on image quality, tie point quality.

\section{Topographic Processing}

155 The DSM obtained from the image processing software was processed in ArcGIS 10.6 (ESRI, 156 2018). Slope, aspect, and a compound topographic index (CTI) (Sorensen et al., 2006) were 157 generated at $4 \mathrm{~cm}$ resolution (see Figure 3) to be compatible with the RGB data. These figures 158 show a subset of the data, and the gully features used for the Carbon loss estimation.

159 These data were then combined to yield a 6 band raster image containing red, green, blue, slope, 160 aspect, and CTI values at $4 \mathrm{~cm}$ resolution. 
Page $\mathbf{8}$ of $\mathbf{2 2}$

161

162

163

164

165

166

167 The image obtained from the SfM procedures in Photoscan was processed using only the red, 168 green and blue colourspace.

169 Scenario 2: Image Classification using Surface features and Original RGB Bands

170 The final image was processed using the red, green and blue colourspace, together with surface 171 characteristics (gullies, edges) derived from the digital surface. The additional surface 172 characteristics were added as separate bands to the image. These were slope, aspect, and CTI, all 173 generated from the surface model at $4 \mathrm{~cm}$ resolution in ArcGIS 10.6 (ESRI, 2017).

174 The Random Forest (RF) classifier is an ensemble method that combines CART (Classification 175 And Regression Trees) with bootstrap aggregating techniques (Breiman et al., 1984). Random 176 Forests grow a number of binary classification trees by selecting a random sample with 177 replacement from the training set (bootstrap aggregating or bagging) for each tree (Breiman, 178 1996). The predicted class for observations in the training set is the most frequent class in the 179 trees for which the observation is a member. This process is described as "voting" (Breiman et 180 al., 1984). The RF algorithm outputs the class label that received the majority of votes, and a 181 probability estimate is derived for each pixel based upon the percentage of votes. The 6 band 182 raster image, and companion training data for the 8 classes (Table 4) were supplied as inputs to 
Page $\mathbf{9}$ of $\mathbf{2 2}$

183 the algorithm, and the algorithm was processed in R (R Core Team 2015) using the Random

184 Forest package by Liaw and M. Wiener (2002), and Horning (2013)

185 Field data Processing: Training data

186 The plant species cover data from the quadrats were automatically assigned to the nearest 187 National Vegetation Classification (NVC), (Rodwell, 1995.) sub-community using the MAVIS 188 program (Smart, 2000) which uses Czekanowski's quantitative index of similarity, taking into 189 account the abundance as well as presence of species (Magurran, 1998). This supervised 190 classification of the data was then visually checked against photographs taken at the date of 191 sampling. If there were discrepancies the assigned class was corrected according to a visual 192 interpretation from the photography. The areas were manually digitised in GIS in order to 193 encapsulate the habitats of a similar type around the plot, so that for a $10 \mathrm{~m}$ diameter zone 194 around each plot, the dominant habitat type was described, and the other habitat areas removed, 195 leaving just the habitat of interest for each plot. For example Sphagnum areas only were 196 digitised, for a plot classed as sphagnum. These vegetation classes were aggregated according to 197 one of 8 types (Table 1) for ease of classification. In addition, 20 ground control points were 198 identified from Environment Agency Lidar 2m DSM (Environment Agency (C) 2015) at fixed 199 locations identified using 25cm Aerial imagery (Infoterra, C 2014).

\section{Field data processing: Validation data}

201 Validation points were randomly stratified across the 8 classes in ArcGIS 10.8 (ESRI, 2016), 202 with 10 points within each class. These points were then used to sample the classifications and 203 assess the performance of the random forest classification.

\section{Evaluation and validation}


Page $\mathbf{1 0}$ of $\mathbf{2 2}$

205 To assess the accuracy of an image classification, a confusion matrix was created which 206 compared the classification results with the validation data. This identifies the nature of the 207 classification errors, as well as their quantities. Confusion matrices were produced from the 208 overlay of the validation areas and the resultant spatial classification. Overall Accuracy (OA) 209 values were computed from confusion matrices in order to evaluate the accuracy of the produced 210 land cover maps (Congalton, 1991). User and producer accuracy was also calculated. Producer 211 accuracy is the fraction of correctly classified pixels with regard to all pixels of that ground truth 212 class, whereas user accuracy (or reliability) is the fraction of correctly classified pixels with 213 regard to all pixels classified as this class in the classified image. A kappa statistic (Cohen, 214 1960), that compares the accuracy of the system to the accuracy of a random system, was 215 computed against the validation data. Probability estimates derived from the model (the 216 percentage votes for each pixel) were grouped by class, and the mean taken for each group to 217 assess the quality of the predictions.

\section{Carbon loss Estimation}

219 The area surveyed at Moor House contains a number of erosion features and gullies. One gully is 220 of considerable size, and an estimate of the net loss of carbon through the peat degradation and 221 erosion is of interest. From previous studies of the site, a measurement of the eroding gully 222 carbon density is $69.84 \pm 2.74 \mathrm{mg} \mathrm{C} \mathrm{cm}^{3}$ (Whitfield 2012). The area of the gully was first 223 covered with a hypothetical surface (assumed flat) at $4 \mathrm{~cm}$ spatial resolution, to cover the edges 224 of the gully, and only where bare peat was exposed. This follows the method of Evans and 225 Lindsay (2010), who used linear interpolation of the DEM between gully edges defined from the 226 gully map to create a 'pre-erosion' surface; and then subtracted the contemporary surface from 227 the pre-erosion surface to create a gully depth map. Using a cut - fill model in QGIS (QGIS 
Page 11 of 22

228 Development Team, 2017), a hypsometric model of the eroded gully was then created. Using this

229 estimate of volume and the carbon density measurements for the Moor House site allowed an

230 estimate of the carbon loss to be calculated.

\section{Results}

232 The SfM derived imagery yielded a $4 \mathrm{~cm}$ resolution orthomosaic (Figure 1). The elevation model 233 obtained from the image processing was used to compute the aspect, slope and topographic index 234 maps shown in Figures 3. The classifications computed by the RF classifier yielded the 235 classification maps and probability estimates in Figures 4 to 7 .

236 Confusion matrices were produced to assess the accuracy of the classified image using both data 237 input scenarios (Table 2 and 3). These matrices show the accuracy of the predictions for the 238 external validation areas, which are independent of the training areas used for establishment of 239 the classification models. For scenario 1, using RGB data only, the classification accuracy per 240 class varied between 40 and $100 \%$. The highest classification accuracy in this case was for 241 coniferous woodland, with the lowest being for bare peat. The overall kappa coefficient was 0.66 242 (Table 2). For scenario 2, using RGB and surface topography data, the classification accuracy 243 per class varied between 50 and $100 \%$. The highest classification accuracy was for conifer 244 plantation, and the lowest was for bare peat. The overall kappa coefficient was slightly higher at 2450.68 (Table 3$).$

246 Mean probability values for each classification are shown in Figure 7 and ranged from 41\% 247 (Saturated bog) to 67\% (coniferous woodland). For all classes, the mean classification 248 probability was higher for the RGB plus topography classification.

249 Carbon loss estimate 
Page $\mathbf{1 2}$ of $\mathbf{2 2}$

250 The volume of material lost in the formation of the gully, assuming an intact blanket bog 251 formation prior to erosion, was estimated as $6,273 \mathrm{~m}^{3}$. The carbon density for gullies at Moor 252 House is $69.84 \pm 2.74 \mathrm{mg} \mathrm{C} \mathrm{cm}^{3}$. Therefore the estimated carbon that has been lost from the 253 gully is estimated to be between 420 and 455 tonnes of C.

\section{Discussion}

255 The results of the image classification using a Random Forest classifier are encouraging, and 256 demonstrate the potential for rapid reconnaissance and monitoring of blanket bog condition (per 257 se) nationally. Incorporation of surface feature data derived from SfM techniques improved the 258 classification accuracy. The incorporation of surface data improves the classification by defining 259 those areas where water accumulates in the landscape, thereby assisting the classification of the 260 smaller Sphagnum bog areas. Incorporation of surface topography improved the predictive 261 accuracy, in part due the presence of specific habitats in dry or wet areas of the blanket bog. For 262 example Sphagnum carpet is only ever found in specifically wet channels or funnels at the Moor 263 House site. Conversely, exposed bare peat may only be found on the flat tops or edges of the 264 blanket bog (Bower, 1961), where water accumulates, and hard frost and wind can attack the 265 structure of the peat. The centre of the blanket bog is characterised by a large eroding mass of 266 peat. This is not surprising since peat erosion is associated with high levels of exposure and 267 precipitation (Bragg, 2001; Yeloff et al. 2005). The Random Forest classifier accurately predicted 268 all classes specified in the training data. Interestingly, although the classification accuracy (user 269 accuracy) for bare peat was $50 \%$, saturated bog, water and sphagnum were higher, ranging 270 between $80 \%$ and $90 \%$. Saturated bog, water and bare peat habitats are often in very close 271 proximity in the study area, and only by using aerial photography at $4 \mathrm{~cm}$ resolution could we 
Page 13 of 22

272 locate habitat patches at such fine a scale. Future studies could look at how much bare peat exists

273 elsewhere in the study area, in addition to the central exposed peat area.

274 The probability of the classification is slightly higher for all classes when topography is used in 275 addition to the RGB data. This may in part be due to high spatial variability in the surface 276 topography exceeding that encompassed within the training data. Also, the incorporation of more 277 predictor variables in Random Forests may yield greater certainty, as a result of the model 278 structure. The mean probability estimates are acceptable (i.e. generally above the default value of 279 0.5), however it is worth noting that Random Forest classifiers normally give good estimates 280 (Belgiu and Dragut 2016), probably due to the transitional nature of upland habitats. Further 281 studies should explore the effect of sample data collection and survey date on the classification. 282 In some cases an accurate Random Forests model can give poor probability estimates (Yang et 283 al. 2016), so the percentage of correctly classified test data is the most common criterion to 284 evaluate models (Bostrom 2007). Therefore comparison of both scenarios accuracies based on 285 mean probabilities could be misleading.

286 Although the vegetation survey data and the aerial survey were six years apart, the use of site 287 photography taken on the date of the vegetation survey (2010) allowed a comparison of the 288 present situation with the state of the land surface in 2014 to be accomplished, and showed that 289 vegetation composition was not significantly different. We cross referenced photographs from 290 the study site taken at the time of the botanical survey, with $25 \mathrm{~cm}$ resolution aerial photography, 291 and our own orthorectified imagery to ensure that the training areas had not changed 292 significantly, thus minimising any uncertainty associated with the classification of training areas.

293 Ideally, vegetation surveys should be undertaken at least during the same year of the aerial 294 survey to reduce this uncertainty. 
Page 14 of 22

295 As with all modelling and data collection methodologies there are uncertainties arising from the

296 various stages of data acquisition, and implicit uncertainties in the modelling, either as a result of

297 the data or the structure of the modelling framework. The uncertainties in the data may arise

298 through the temporal mismatch between the date of image acquisition and the land survey, and

299 this may explain some of the misclassification of water as peat and vice versa.

300 The purpose of this study was to investigate the area of blanket peatland under erosion, and

301 quantify the apparent losses. This was achieved with some success, but also some uncertainty,

302 since the volume of intact blanket peatland prior to the formation of gully and erosion features

303 can never be fully known. The true volume of carbon that has been lost cannot be calculated,

304 since the bog would have gradually lost and simultaneously sequestered carbon through 305 revegetation and recovery over time. Also, the hypothetical surface used to calculate the volume 306 could be Estimating a value is, however, useful in providing the conservation scientist with a 307 value associated with the formation of gully features, and what could potentially be recovered 308 through habitat restoration.

309 The methodology, combining ground- and UAV-based survey, and ground control points based 310 on static objects, is readily transferable to other sites containing different habitats. When 311 combined with topographic indices, slope and aspect, RGB data can be extremely useful in 312 remote areas where habitat classification can be difficult due to limited access or data 313 availability. Although ground control points should normally be located using a high accuracy 314 GPS unit, such systems were unavailable to the team at the time, and the purpose of this study 315 was to minimise impact at the site, especially in the upland saturated bog environment. Future 316 studies could however make use of onboard RTK systems for improved camera location 317 accuracy, and improved ground control point accuracy for the static locations. While 
Page 15 of 22

318 hyperspectral data from UAVs are still expensive to obtain, the approach provided here can 319 provide equivalent outputs with a similar level of accuracy. UAVs may therefore fill the gap 320 between land surveys and satellite imagery. UAVs do have some drawbacks compared to more 321 traditional sources of remote sensing data. Specifically, UAVs are more limited in their sensor 322 payload, and therefore the complexity of sensors that they can carry, although this is due to a 323 combination of cost, ease of use and regulations. UAVs are also more susceptible to high winds 324 and adverse weather compared to manned aircraft. Wind speeds above 15 knots ( $35 \mathrm{mph}$ ) 325 typically lead to poor image capture from a UAV. Individual flights cover much smaller areas 326 compared to manned aircraft and satellites. Therefore more flights are required to cover larger 327 areas and more time is required to process the imagery produced. Larger areas (multiple $\mathrm{km}^{2}$ ) 328 could be captured per flight using fixed wing UAVs, however this approach is limited by visual 329 flight rule requirements. RGB data from UAV platforms can also fill the gap between field and 330 satellite imagery, which are either labour intensive or conversely too coarse resolution to 331 separate distinct habitats within the broad habitats. UAV hyperspectral data are still prohibitively 332 expensive, so the combination of UAV RGB data with topography data can be useful for upland 333 habitats in the UK where the access is difficult and availability of satellite imagery is low due to 334 cloud coverage.

\section{Conclusions}

336 There is a greater availability of UAV platforms providing RGB imagery at present, owing in 337 part to the expense of hyperspectral instruments. This study demonstrates that for large areas of 338 fairly homogenous and well defined habitats, habitat classifications may be produced in a 339 relatively cheap and easy way using consumer grade cameras and relatively inexpensive fixed 340 wing UAV platforms. Remote sensing of upland sites in the UK can be difficult due to cloud 


\section{Page $\mathbf{1 6}$ of $\mathbf{2 2}$}

341 cover, and therefore UAVs may offer an effective and realistic alternative. Combined with open 342 source software approaches for image classification, this approach presents new opportunities for 343 directing, and monitoring the success of peatland conservation schemes. As a specific means of 344 measuring success, carbon loss estimates can be readily generated using the UAV imagery and 345 SfM techniques described here.

\section{Acknowledgments}

347 We thank the NERC Centre for Ecology and Hydrology for providing the internal funding for 348 the purposes of this work. 
Page 17 of 22

\section{References}

351 Anderson, K., Bennie, J.J., Milton, E.J., Hughes, P.D.M., Lindsay, R., \& Meade, R. (2010)

352 Combining LiDAR and IKONOS Data for Eco-Hydrological Classification of an Ombrotrophic 353 Peatland. Journal of Environmental Quality, 39, 260-273

354 Anderson, K. and Gaston, K. J. (2013) Lightweight unmanned aerial vehicles will revolutionize 355 spatial ecology. Frontiers in Ecology and the Environment, 11: 138-146. doi:10.1890/120150

356 Belgiu, M., \& Dragut, L. (2016). Random forest in remote sensing: A review of applications and 357 future directions. Isprs Journal of Photogrammetry and Remote Sensing, 114, 24-31

358 Bostrom, H. (2007) Estimating class probabilities in random forests. In Machine Learning and 359 Applications, 2007. ICMLA 2007. Sixth International Conference on, pp. 211-216. IEEE, 2007.

360 Boyle S.A., Kennedy C.M., Torres J., Colman K, Pérez-Estigarribia P.E., de la Sancha N.U.

361 (2014). High-Resolution Satellite Imagery Is an Important yet Underutilized Resource in

362 Conservation Biology. Peter H-U, ed. PLoS ONE., 9(1):e86908.

363 doi:10.1371/journal.pone.0086908.

364 Bower M, (1961). The distribution of erosion in blanket peat bogs in the Pennines. Transactions 365 of the Institute of British Geographers, 29: 17-30

366 Bragg, O M \& J H Tallis, (2001) The sensitivity of peat-covered upland landscapes. Catena, 42: $367 \quad 345-360$.

368 Breiman L. (2001) Random Forests. Machine Learning, 45, 5-32. 
Page $\mathbf{1 8}$ of $\mathbf{2 2}$

369 Breiman, L., Friedman, J. H., Olshen, R. A., \& Stone, C. J. (1984) Classification and regression 370 trees. Monterey, CA: Wadsworth \& Brooks/Cole Advanced Books \& Software. Breiman, L.

371 1996. Bagging Predictors. Machine Learning 24:123-140.

372

373

Cohen, J. (1960) A coefficient of agreement for nominal scales. Educational and Psychological 374 Measurement 20, 37-46.

375 Congalton RG. (1991) A Review of Assessing the Accuracy of Classifications of Remotely 376 Sensed Data. Remote Sensing of Environment 37: 35-46.

377 Dye, M., Mutanga, O., \& Ismail, R. (2012) Combining spectral and textural remote sensing 378 variables using random forests: predicting the age of Pinus patula forests in KwaZulu-Natal, 379 South Africa. Journal of Spatial Science, 57, 193-211

380 Environmental Systems Research Institute (ESRI) (2010). ArcGIS Release 10. Redlands, CA.

381 Evans, C.D., Bonn, A., Holden, J., Reed, M.S., Evans, M.G., Worrall, F., Couwenberg, J., \& 382 Parnell, M. (2014) Relationships between anthropogenic pressures and ecosystem functions in 383 UK blanket bogs: Linking process understanding to ecosystem service valuation. Ecosystem 384 Services, 9, 5-19

385 Evans, M. and Lindsay, J. (2010) High resolution quantification of gully erosion in upland 386 peatlands at the landscape scale. Earth Surface Processes and Landforms, 35: 876-886.

387 doi:10.1002/esp.1918

388 Freeman, C., Evans, C.D., Monteith, D.T., Reynolds, B., \& Fenner, N. (2001) Export of organic 389 carbon from peat soils. Nature, 412, 785-785

390 Gislason P.O., Benediktsson J.A., \& Sveinsson J.R. (2006) Random Forests for land cover 391 classification. Pattern Recognition Letters, 27, 294-300. 
Page 19 of 22

392 Glendell, M., McShane, G., Farrow, L., James, M. R., Quinton, J., Anderson, K., Evans, 393 M., Benaud, P., Rawlins, B., Morgan, D., Jones, L., Kirkham, M., DeBell, L., Quine, T. A., Lark, 394 M., Rickson, J., and Brazier, R. E. (2017) Testing the utility of structure-from-motion 395 photogrammetry reconstructions using small unmanned aerial vehicles and ground photography 396 to estimate the extent of upland soil erosion. Earth Surface Processes and Landforms, 42: 1860397 1871. doi: 10.1002/esp.4142.

398 Gorham, E. (1991) Northern peatlands: role in the carbon cycle and probable responses to 399 climatic warming. Ecological Applications, 1: 182-195

400 Holden J. (2005) Peatland hydrology and carbon release: why small-scale process matters.

401 Philosophical Transactions of the Royal Society a-Mathematical Physical and Engineering 402 Sciences 363: 2891-2913.

403 Horning, N. (2013) Training Guide for Using Random Forests to Classify Satellite Images - v9. 404 American Museum of Natural History, Center for Biodiversity and Conservation. Available from 405 http://biodiversityinformatics.amnh.org/. https://doi.org/10.5285/7a7d08e3-48e2-4aad-855b406 9d6767b9ae9b

407 Joosten H., Tapio-Biström M.-L. \& Tol S. (eds) (2012) Peatlands -guidance for climate change 408 mitigation through conservation, rehabilitation and sustainable use. 2nd ed. FAO and Wetlands 409 International, Rome, Italy, 100 pp. ISBN: 978-92-5-107302-5

410 Juel, A., Groom, G.B., Svenning, J.C., \& Ejrnaes, R. (2015) Spatial application of Random

411 Forest models for fine-scale coastal vegetation classification using object based analysis of aerial 412 orthophoto and DEM data. International Journal of Applied Earth Observation and

413 Geoinformation, 42, 106-114 
Page $\mathbf{2 0}$ of $\mathbf{2 2}$

414 Liaw and M. Wiener (2002). Classification and Regression by randomForest. R News 2(3), 18-41522.

416 Littlewood, N., Anderson, P., Artz, R., Bragg, O., Lunt, P. and Marrs, R. (2010) Peatland

417 biodiversity. Report to IUCN UK Peatland Programme, Edinburgh. www.iucn-uk-

418 peatlandprogramme.org/scientificreviews

419 Magurran, A.E. (1988) Ecological diversity and its measurement. London: Croon Helm Ltd. 179 420 p.

421 Maskell, L.C., Norton, L.R., Smart, S.M., Carey, P.D., Murphy, J., Chamberlain, P.M., Wood, 422 C.M., Bunce, R.G.H. \& Barr, C.J. (2008) Countryside Survey Technical Report No. 1/07 Field 423 Mapping Handbook.

424 http://www.countrysidesurvey.org.uk/sites/default/files/pdfs/reports2007/CS UK_2007_TR1.pdf

425 Mc Morrow, I.M., Cutler, M.E., Evans, M, Alroichdi, A., (2004), hyperspectral indices for 426 characterising upland peat composition. International journal of remote sensing, 25, 313-325.

427 R Core Team (2013). R: A language and environment for statistical computing. R Foundation for 428 Statistical Computing, Vienna, Austria. URL http://www.R-project.org/.

429 QGIS Development Team (2017). QGIS Geographic Information System. Open Source 430 Geospatial Foundation Project. http://qgis.osgeo.org

431 Rodwell, J.S. (ed.) (1995). British Plant Communities. Volume 4. Aquatic communities, swamps 432 and tall-herb fens. Cambridge University Press.

433 Rose, R.J., Wood, C.M., Baxendale, C.L., Whitfield, M.G., Ostle, N.J., Driscoll, B., Looker, A., 434 Looker, G. (2016). Vegetation survey of Moor House National Nature Reserve 2008-2009. 
Page $\mathbf{2 1}$ of $\mathbf{2 2}$

435 NERC Environmental Information Data Centre https://doi.org/10.5285/7a7d08e3-48e2-4aad$436 \quad 855 b-9 d 6767 b 9 a e 9 b$

437 Smart, S.M. (2000) MAVIS: Modular Analysis of Vegetation Information System.: Centre for 438 Ecology and Hydrology, Lancaster, UK. Available: http://www.ceh.ac.uk/services/modular439 analysis-vegetationinformation-system-mavis.

440 Sørensen, R.; Zinko, U.; Seibert, J. (2006) "On the calculation of the topographic wetness index: 441 evaluation of different methods based on field observations". Hydrology and Earth System 442 Sciences. 10: 101-112.

443 Toth C and Jozkow G. (2016) Remote sensing platforms and sensors: A survey. Isprs Journal of $444 \quad$ Photogrammetry and Remote Sensing 115: 22-36.

445 Whitfield, M.G. Peatland diversity and carbon dynamics, Thesis submitted for the degree of 446 Doctor of Philosophy, Lancaster University, September 2012.

447 Yang, F., Piao P., and Qifeng, Z. (2016) A preliminary study on class probability estimation for 448 random forest using kernel density estimators. Computer Science \& Education (ICCSE), 2016 449 11th International Conference on. IEEE, 2016.

450 Yeloff, D.E., Labadz, J.C., Hunt, C.O., Higgitt, D.L., \& Foster, I.D.L. (2005) Blanket peat 451 erosion and sediment yield in an upland reservoir catchment in the southern Pennines, UK. Earth 452 Surface Processes and Landforms, 30, 717-733

453 Yu ZC. (2012) Northern peatland carbon stocks and dynamics: a review. Biogeosciences 9:40714544085.

455 456 
Page $\mathbf{2 2}$ of $\mathbf{2 2}$

457

10

11

12

13

14

15

16

17

18

19

20

21

22

23

24

25

27

28

29

30

31

32

33

34

35

36

37

38

39

40

41

42

43

44

45

46

47

48

49

50

51

52

53

54

55

56

57

58

59

60

http://mc.manuscriptcentral.com/PiPG 


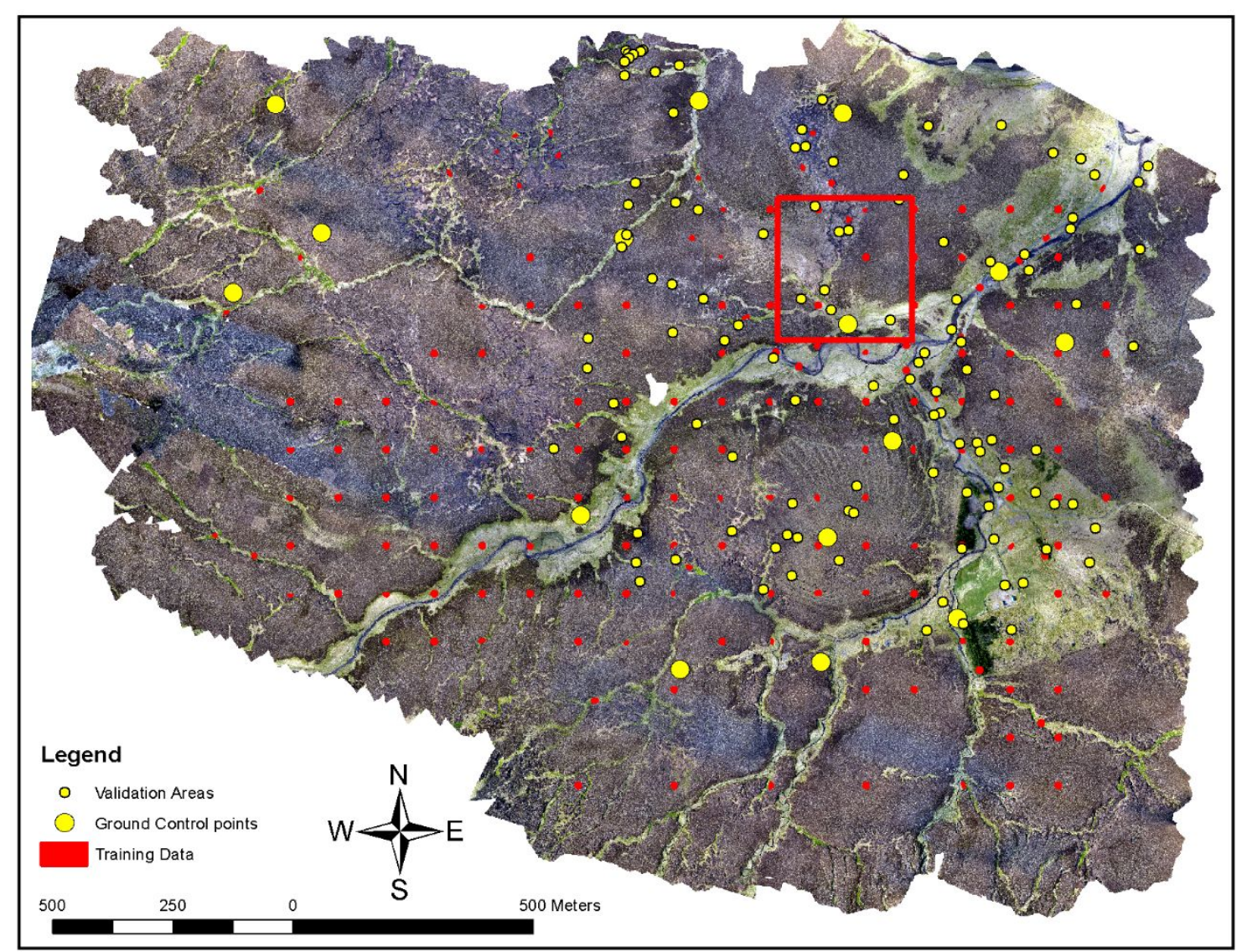

Figure 1 Overview of the Troutbeck study area at Moor House ECN, showing the orthorectified image obtained from 4 UAV flights, ground control points, the model training and validation areas and the focus area (red square). 


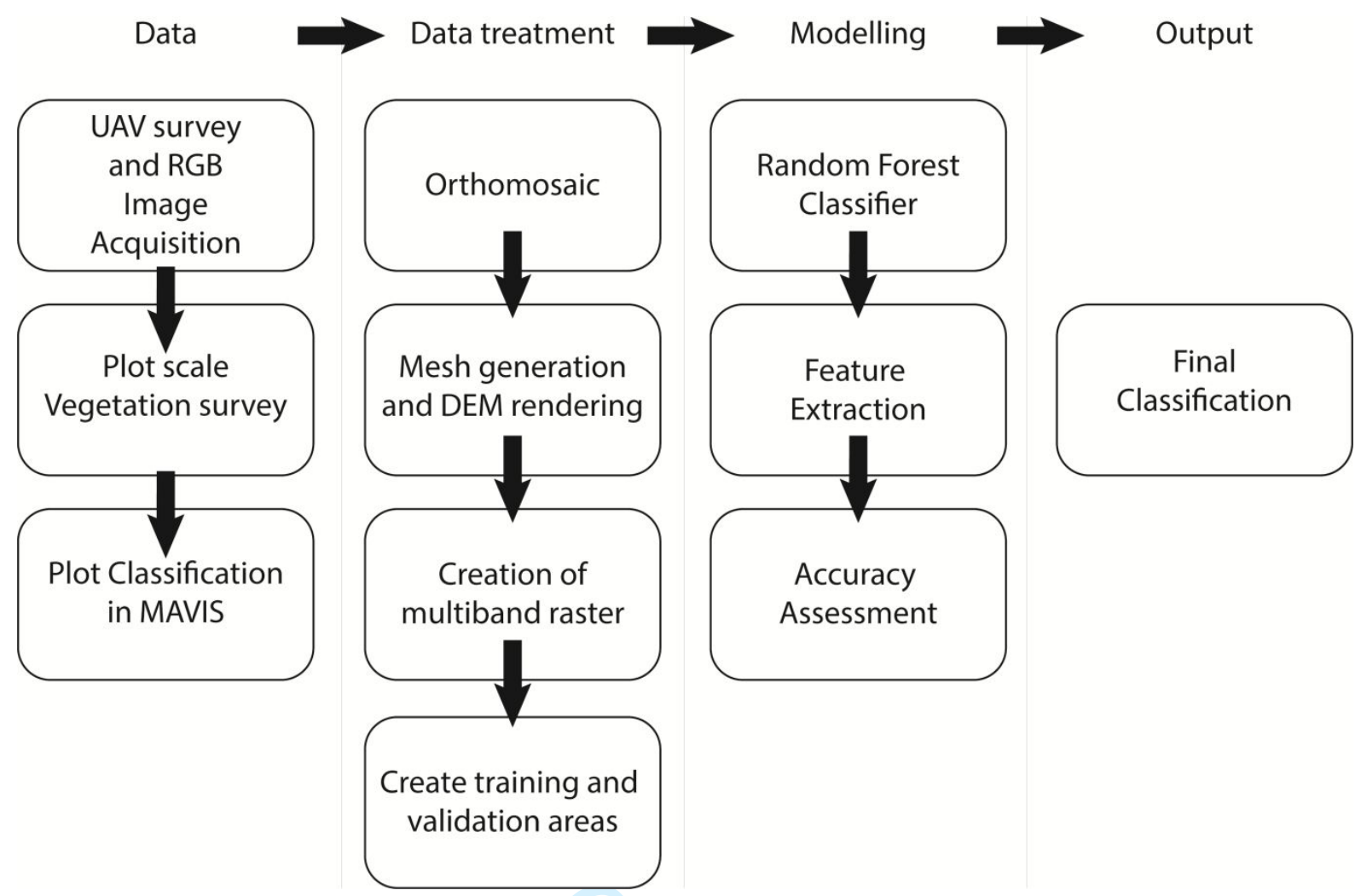

Figure 2 Process flow from image capture to the final habitat classification used in this study. 

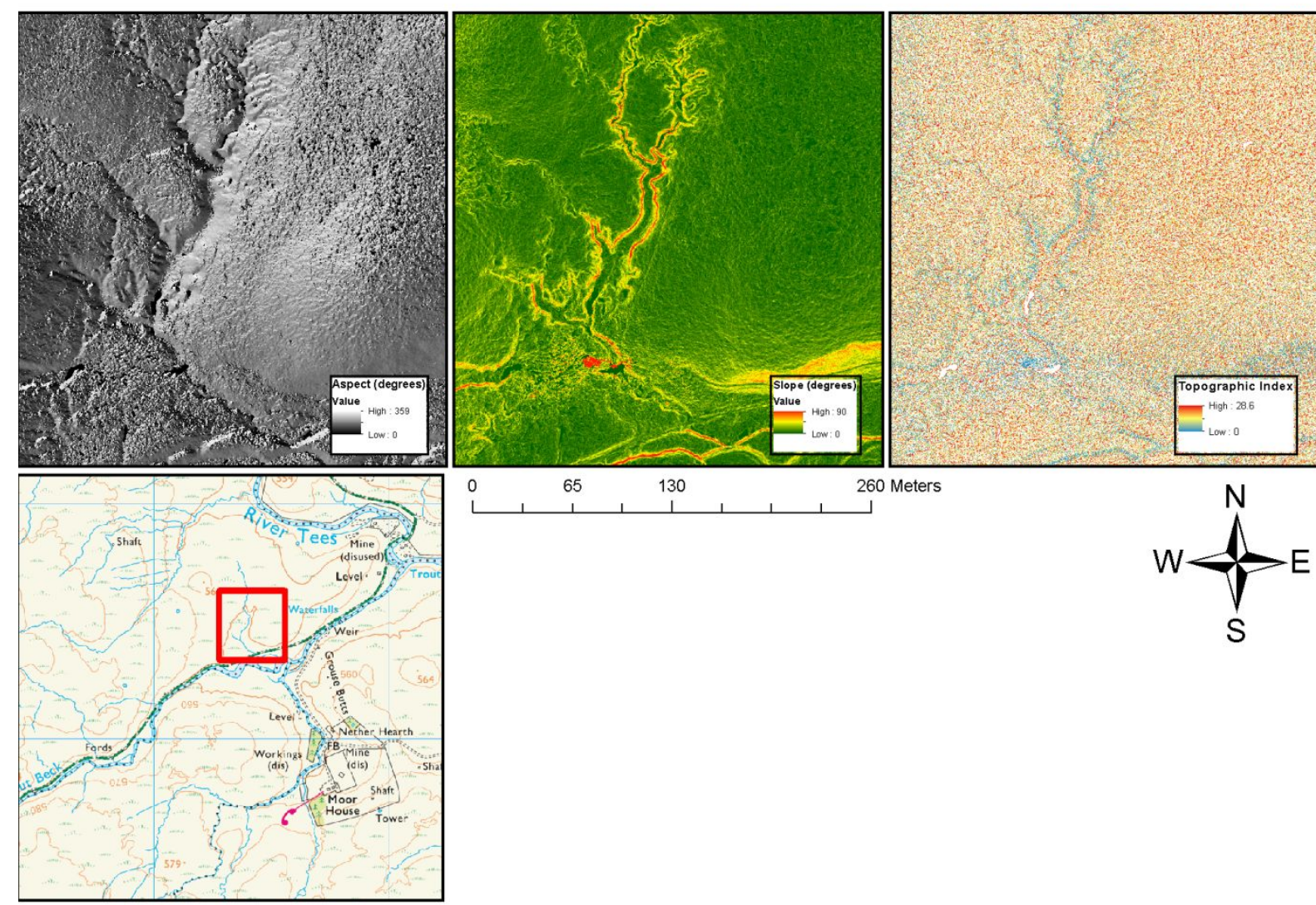

Figure 3 Aspect, slope and topographic index surfaces generated from the surface topography (4 $\mathrm{cm}$ spatial resolution). Area of the eroded gully shown, maps extend across the whole Moorhouse study area. 

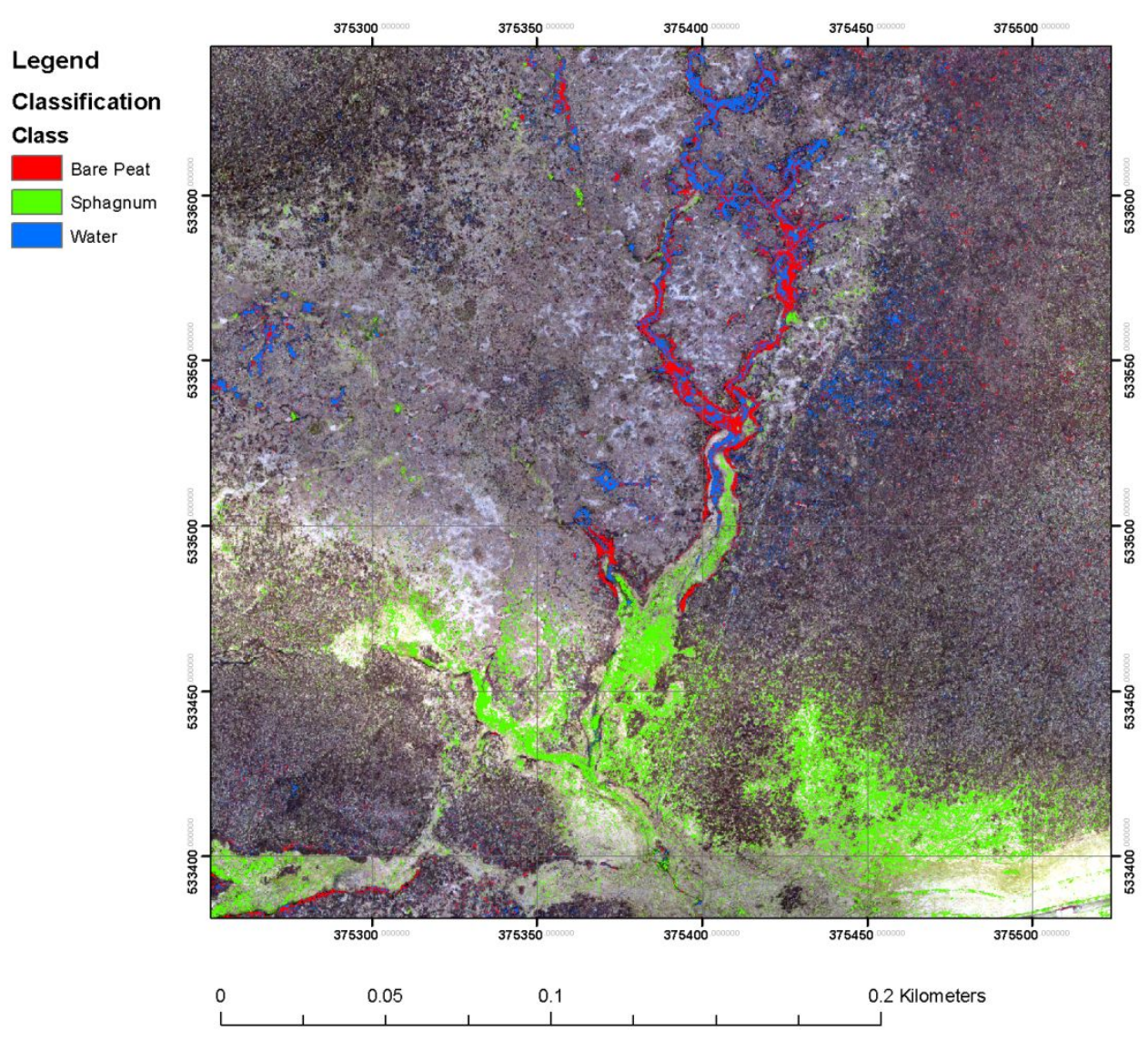

Figure 6 Map showing the bare peat, water and sphagnum habitats as predicted for Moor House with $R G B$ and topographic information for the focus area. 


\section{Legend}

RGB Colourspace Model

Class

Bare Peat

Conifer plantation

Gravel/Road

Northern blanket bog

Rush/moorland grass/streamside

Saturated bog

Sphagnum

Water
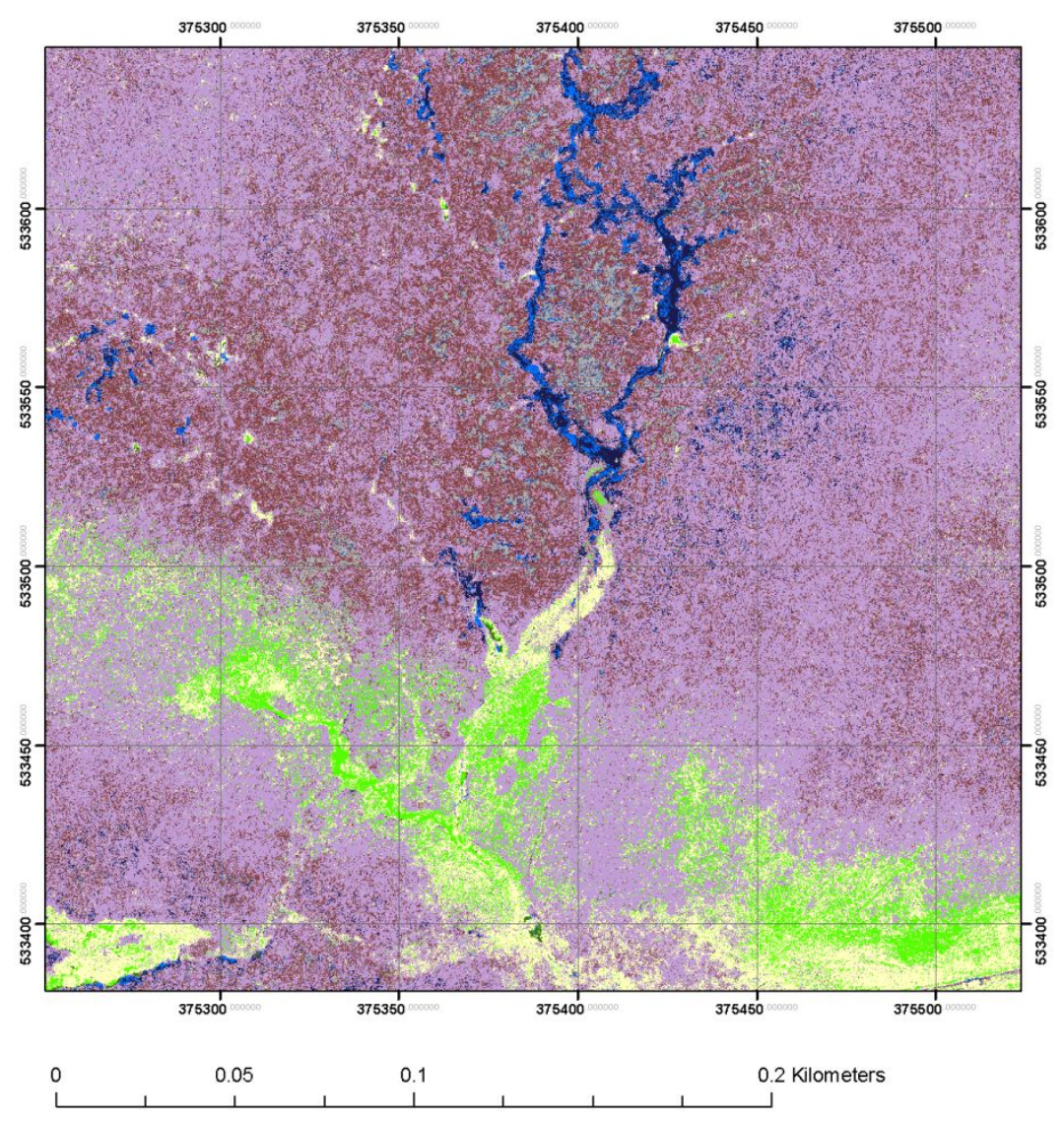

Figure 7 Predicted classes for Moor House using only the RGB data 

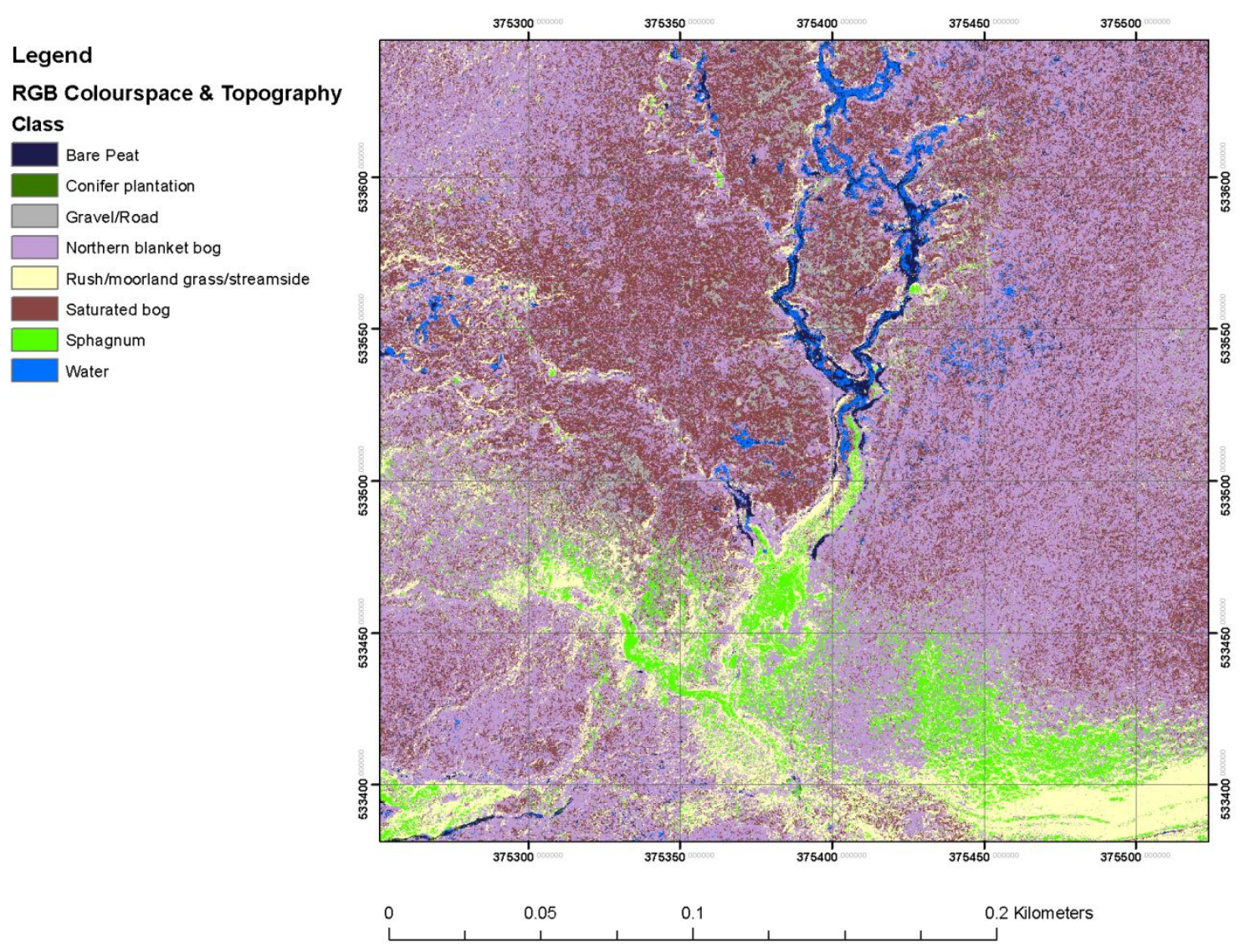

Figure 8 Predicted classes for Moor House using the RGB combined with the topographic information 


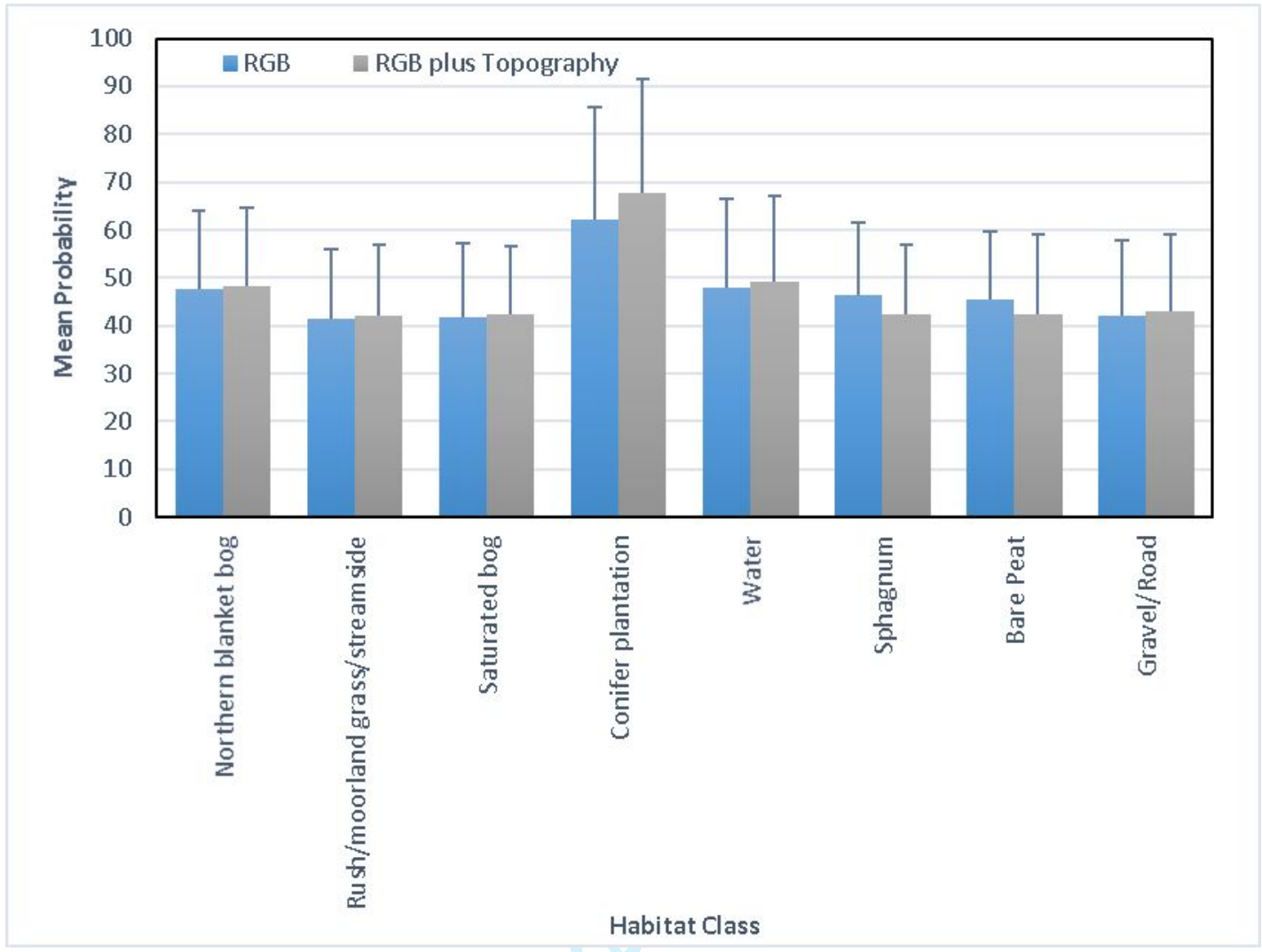

Figure 9 Mean probabilities for each surface summarised for each classification with standard errors. 
Table 1 List of aggregated classes based on the Countryside Vegetation System used in this study

\begin{tabular}{|l|l|}
\hline CVS Class & Aggregate Class \\
\hline Northern Blanket Bog & Northern Blanket Bog \\
\hline Dry heath soil & Bare Peat \\
\cline { 1 - 1 } Bare Peat & \multirow{2}{*}{ Conifer plantation } \\
\cline { 1 - 1 } Young conifer & \multirow{3}{*}{ Goorland Grass } \\
\cline { 1 - 1 } Conifer plantation & \\
\cline { 1 - 1 } River shingle & \\
\cline { 1 - 1 } Streamside/acid grassland & \\
\cline { 1 - 1 } Moorland grass/bog & \\
\cline { 1 - 1 } Moorland grass/heath peat & \\
\cline { 1 - 1 } Marsh/streamside & Saturated bog \\
\cline { 1 - 1 } Moorland grass/heath soil & Sphagnum \\
\hline Heath/moorland grass & Open Water \\
\hline Saturated bog &
\end{tabular}


Table 2 Confusion Matrix for the random forest classification using only the RGB data for Moor House

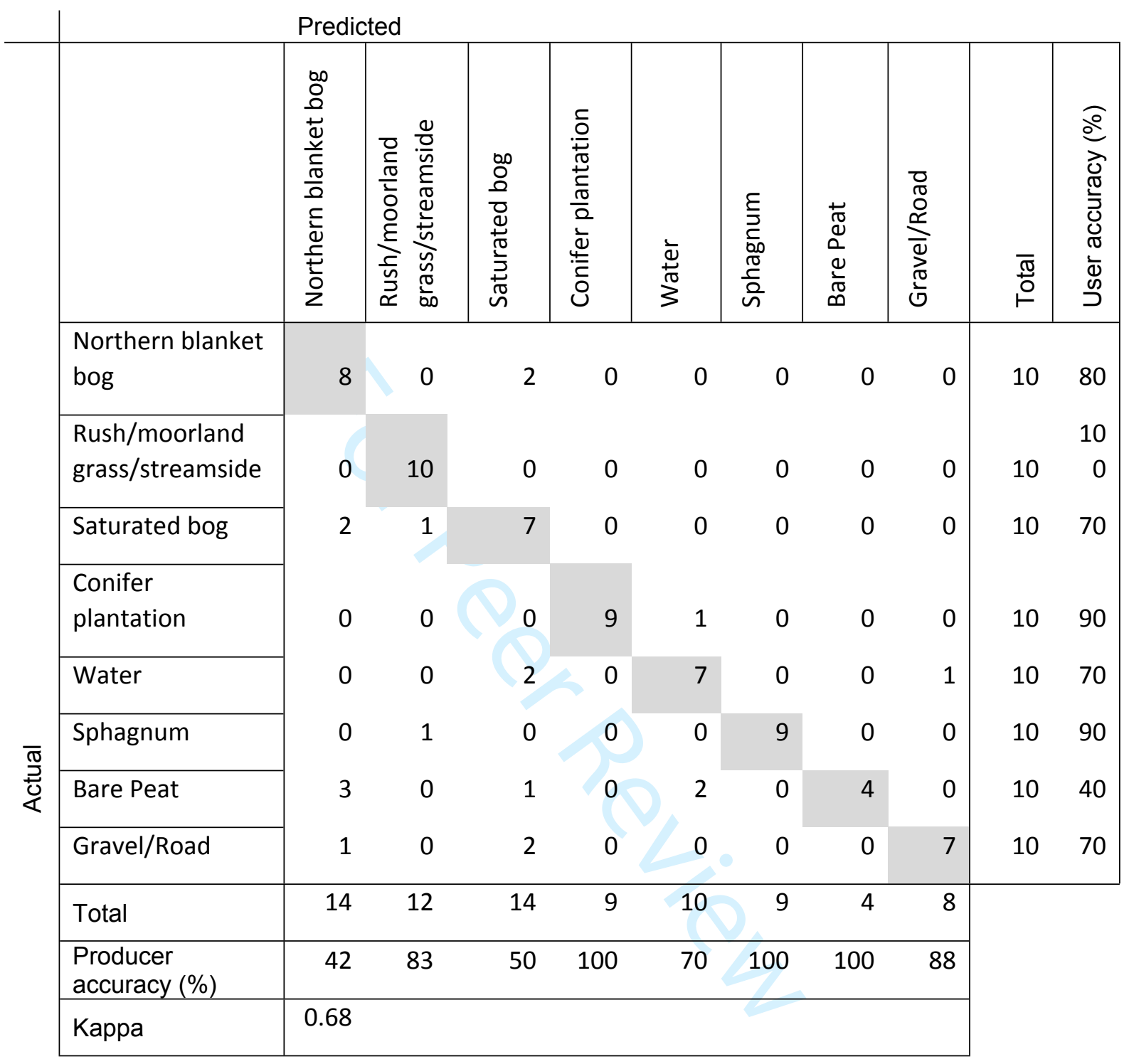


Table 3 Confusion Matrix for the random forest classification using the RGB data and surface topography for Moor House

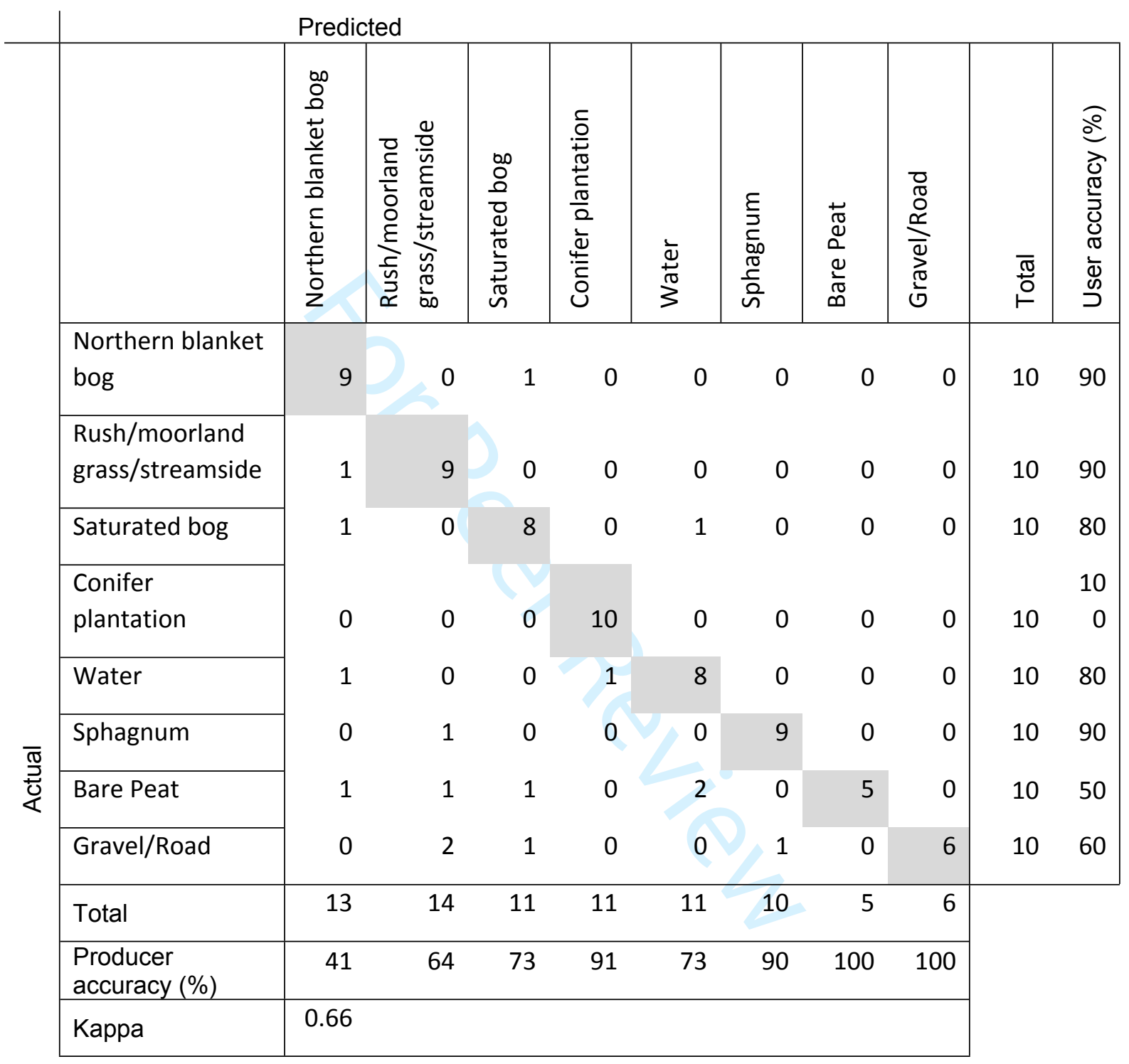


Table 1 Processing parameters used in Agisoft Photocsan for the construction of the orthomosaic and digital surface model

\begin{tabular}{|c|c|}
\hline General & $\begin{array}{l}\text { Cameras } 2207 \\
\text { Aligned cameras } 2207 \\
\text { Markers } 24 \\
\text { Coordinate system OSGB } 1936 \text { / British National Grid } \\
\text { (EPSG::27700) } \\
\text { Rotation angles Yaw, Pitch, Roll }\end{array}$ \\
\hline Point Cloud & $\begin{array}{l}\text { Points } 440,842 \text { of } 638,731 \\
\text { Reprojection error } 1.2099 \text { ( } 7.04299 \text { max }) \\
\text { Point colors } 3 \text { bands, uint8 } \\
\text { Key points No } \\
\text { Average tie point multiplicity } 3.75116\end{array}$ \\
\hline Dense Point Cloud & $\begin{array}{l}\text { Points } 625,020,795 \\
\text { Point colors } 3 \text { bands, uint8 }\end{array}$ \\
\hline Dense Point Cloud Reconstruction parameters & $\begin{array}{l}\text { Quality High } \\
\text { Depth filtering Aggressive }\end{array}$ \\
\hline Model & $\begin{array}{l}\text { Faces } 4,925,688 \\
\text { Vertices } 2,473,776 \\
\text { Vertex colors } 3 \text { bands, uint } 8 \\
\text { Texture } 4,096 \times 4,096,4 \text { bands, uint } 8\end{array}$ \\
\hline Model Reconstruction parameters & $\begin{array}{l}\text { Surface type Height field } \\
\text { Source data Dense } \\
\text { Interpolation Enabled } \\
\text { Quality High } \\
\text { Depth filtering Aggressive } \\
\text { Face count } 5,000,000 \\
\text { Processing time } 20 \text { minutes } 12 \text { seconds }\end{array}$ \\
\hline Model Texturing parameters & $\begin{array}{l}\text { Mapping mode Orthophoto } \\
\text { Blending mode Mosaic } \\
\text { Texture size } 4,096 \times 4,096 \\
\text { Enable hole filling Yes } \\
\text { Enable ghosting filter Yes } \\
\text { UV mapping time } 1 \text { minutes } 37 \text { seconds } \\
\text { Blending time } 9 \text { hours } 46 \text { minutes }\end{array}$ \\
\hline DSM & $\begin{array}{l}\text { Size } 52,504 \text { x } 46,139 \\
\text { Coordinate system OSGB } 1936 \text { / British National Grid } \\
\text { (EPSG::27700) }\end{array}$ \\
\hline DSM Reconstruction parameters & $\begin{array}{l}\text { Source data Dense cloud } \\
\text { Interpolation Enabled } \\
\text { Processing time } 55 \text { minutes } 24 \text { seconds }\end{array}$ \\
\hline Orthomosaic & $\begin{array}{l}\text { Size } 65,494 \times 52,584 \\
\text { Coordinate system OSGB } 1936 \text { / British National Grid } \\
\text { (EPSG::27700) } \\
\text { Colors } 3 \text { bands, uint8 }\end{array}$ \\
\hline Orthomosaic Reconstruction parameters & $\begin{array}{l}\text { Blending mode Mosaic } \\
\text { Surface DEM } \\
\text { Enable hole filling Yes } \\
\text { Processing time } 1 \text { hours } 15 \text { minutes }\end{array}$ \\
\hline
\end{tabular}


Table 5. Control points RMSE and ground control point (GCP) errors , ( $X$ - Easting, $Y$

- Northing, Z - Altitude).

\begin{tabular}{|c|c|c|c|c|c|c|}
\hline $\begin{array}{l}\text { Point } \\
\text { type }\end{array}$ & Count & $X$ error $(m)$ & $Y$ error (m) & $Z$ error $(m)$ & $X Y$ error (m) & Total $(\mathrm{m})$ \\
\hline Control & 15 & 1.75774 & 0.485608 & 1.43344 & 1.82359 & 2.31953 \\
\hline \multirow{25}{*}{ GCP } & Label & $X$ error $(m)$ & $Y$ error $(m)$ & $Z$ error $(m)$ & Total (m) & Image (pix) \\
\hline & Bridge & -0.469988 & -0.100511 & -0.728492 & 0.87275 & $0.000(1)$ \\
\hline & point 1 & & & & & \\
\hline & point 2 & -0.499273 & 0.0301792 & 0.249121 & 0.55879 & $0.000(1)$ \\
\hline & point 3 & -0.936561 & -0.487554 & -1.5222 & 1.85256 & $0.002(4)$ \\
\hline & point 4 & 2.05486 & -0.616093 & -3.03196 & 3.71413 & $0.002(2)$ \\
\hline & point 5 & & 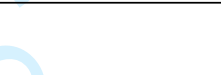 & & & \\
\hline & point 6 & 0.0944338 & 0.510288 & 0.282165 & 0.590702 & $0.000(1)$ \\
\hline & point 7 & & & & & \\
\hline & point 8 & 0.220504 & -0.0945066 & 1.2857 & 1.30789 & $0.005(7)$ \\
\hline & point 9 & 0.261059 & -0.448917 & 2.29679 & 2.35477 & $0.003(3)$ \\
\hline & point 10 & -0.106125 & -0.870693 & -1.06144 & 1.37696 & $0.005(3)$ \\
\hline & point 11 & 0.384385 & -0.632363 & 0.320792 & 0.806562 & $0.001(3)$ \\
\hline & point 12 & 0.659767 & 0.174325 & -1.05869 & 1.25956 & $0.003(4)$ \\
\hline & point 13 & & & 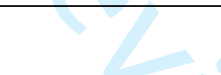 & & \\
\hline & point 14 & & & & & \\
\hline & point 15 & & & & 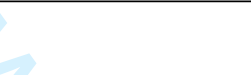 & \\
\hline & point 16 & -6.03509 & -0.503942 & -1.11076 & 6.15711 & $0.002(3)$ \\
\hline & point 17 & & & & & \\
\hline & point 18 & & & & & \\
\hline & point 19 & 1.41136 & -0.343287 & 1.09074 & 1.81645 & $0.003(3)$ \\
\hline & point 20 & 0.972456 & 0.651922 & 1.50597 & 1.90752 & $0.003(3)$ \\
\hline & point 21 & 0.823755 & 0.0132818 & 2.07568 & 2.2332 & $0.002(3)$ \\
\hline & point 22 & & & & & \\
\hline & point 23 & -0.128602 & 0.67285 & -0.600468 & 0.910949 & $0.002(2)$ \\
\hline
\end{tabular}

